\title{
UK consumer attitudes, beliefs and barriers to increasing fruit and vegetable consumption
}

\author{
David N Cox ${ }^{1, *}$, Annie S Anderson ${ }^{2}$, Michael EJ Lean ${ }^{3}$ and David J Mela ${ }^{1}$ \\ 'Consumer Sciences Department, Institute of Food Research, Earley Gate, Reading RG6 6BZ, UK: \\ ${ }^{2}$ Department of Human Nutrition, University of Glasgow, UK: ${ }^{3}$ Department of Human Nutrition, \\ University of Glasgow, UK
}

Received 12 Seplember 1997: Accepted 10 December 1997

\begin{abstract}
Objectives: To assess attitudes, predictors of intention, and identify perceived barriers to increasing fruit and vegetable (F\&V) intakes.

Design: UK nationwide postal survey utilizing the theory of planned behaviour.

Subjects. Stratified (by social class and region) random sample of 2020 UK adults providing a modest response rate of $37 \%(n=741)$.

Results: Belief measures (e.g. health, cost, taste, etc.) were strongly associated with overall attitudes which were reported as being largely favourable towards fruit, vegetables and, to a lesser extent, vegetable dishes, and were strongly associated with reported intention to increase consumption. Subjects reported they could increase their consumption, but this was only weakly associated with intention to do so. Approximately $50 \%$ of respondents reported an intention to increase intakes. Social pressure was strongly associated with reported intention to increase; however, scores indicated low perceived social pressure to change. Evidence of unrealistic optimism concerning perceived intakes and the perceived high cost of fruit may also act as barriers.

Conclusions. Results from this study suggest a lack of perceived social pressure to increase F\&V intakes and suggests that public health efforts require stronger and broader health messages that incorporate consumer awareness of low present consumption.
\end{abstract}

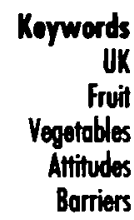

A diet rich in fruit and vegetables (F\&V) has many health benefits ${ }^{1,2}$. Epidemiological ${ }^{3,4}$, clinical $^{5}$ and biochemical studies have demonstrated the benefits of the nutrient and non-nutrient ${ }^{6}$ constituents of F\&V. Recommended dietary F\&V intake is at least $400 \mathrm{~g}$ per person per day ${ }^{7,8}$, which has been translated into a minimum of 5 or 6 portions (each of approximately $80 \mathrm{~g}$ ) per day ${ }^{9}$. Large-scale public health campaigns are promoting 5-F\&V-portions-a-day in the USA ${ }^{10,11}$ and in the UK, health educators ${ }^{12,13}$, producers ${ }^{14}$ and several large food retailers have been involved in 5-a-day promotions.

Average $F \& V$ (excluding potatoes) intakes in the UK are approximately $244 \mathrm{~g}$ (about 3 portions) per person per day ${ }^{15}$. Trends from the UK National Food Survey (NFS) recorded only a slight increase in F\&V quantity purchased between 1990 and $1994^{16}$. When NFS data were adjusted for edible portions, the average consumption remained approximately 3 portions per person per day with significant sections of the population, especially in lower income and manual occupations, consuming considerably less (C Williams \& M Marmot, 1995, unpublished data). In Scotland, average F\&V intake has been estimated at only 2.4 portions per day ${ }^{17}$.

The present study sought to identify relevant beliefs and attitudes of the UK population towards increasing F\&V that may act as barriers to the implementation of current health messages and expanded upon issues raised by some of the present authors (Anderson and Lean) in an earlier study ${ }^{18}$ in Scotland. Reported here is the first part of a larger study that ultimately seeks to identify strategies enabling UK consumers to increase their F\&V consumption successfully.

UK definitions of F\&V items ${ }^{19}$ were adopted, specifically including vegetable dishes of Mediterranean and Asian origin (which may act as an important medium for increased consumption) and pure unsweetened fruit juice. Potatoes, other tubers and fruitflavoured products were excluded in line with UK 5a-day messages ${ }^{9,12,13,14}$ which view the main nutritional and culinary function of potatoes in the UK diet as a source of starch ${ }^{19}$. This paper describes initial results of the whole sample and individuals categorized by self-reported fruit, vegetable, and total F\&V consumption. 


\section{Methodology}

\section{Subject recruitment and contact}

A stratified random sample of 2020 adults ( 18,85 years), derived from the 1991 Census of all UK households (CACI Information Services, London). The expected response rate of $\approx 50 \%$ was intended to be representative of the UK population providing sufficient power to allow comparison between selected population subgroups (sex, social class, region). The sample was stratified by social class (of head of household) according to region but weighted towards both Scotland and unskilled manual workers because of a specific interest in the former and to offset poor response rates predicted from the latter, and excluded persons living in institutions. Potential subjects were sent a postcard advising them of the purpose and imminent arrival of the questionnaire (September 1994). To maximize returns, questionnaire packets included a pen and postage-paid return envelope, followed by two reminder/thank you letters.

\section{Questionnaire design}

The final questionnaire* was in four parts, and developed following face-to-face interviews $(n=30)$ and postal pre-testing of draft versions $(n=50)$. These subjects provided both open comments and responses to structured questions on clarity, comprehension and ease of use but their responses were excluded from the analysis reported below.

Part 1 was comprised of questions on attitudes, beliefs, and outcome evaluations based upon the theory of planned behaviour (TPB) ${ }^{20}$. The methodology (see below for a more detailed description of TPB) and questions on beliefs were adapted from a similar approach used in a study of attitudes and beliefs about changing to a low-fat diet ${ }^{21}$ which proved to be a reliable and valid method for predicting intention, which in turn is considered to be an important predictor of behavioural change ${ }^{20}$.

After specifically defining the fruits, vegetables or vegetable dishes of interest, the belief questions (see Appendix 1) were of the format: 'Increasing the amount of I I eat means choosing foods which...', followed by 11 statements concerning health, cost, satiety, taste, chewing and digestion, nutrient value, weight control, ease of preparation and cooking, family preference, motivation, and fitting into eating habits. These were scored on a 7-point scale from strongly disagree (-3), through neutral (0), to strongly agree (+3) with scales labelled at intermediate points. Corresponding outcome evaluation statements, for example, 'Choosing foods which protect my health',

-Copies of the original questionnaire may be obtained, up to 18 months from date of publication, from the senior author (Cox) upon request. were scored 1,7 on the basis of their importance to the respondent (extremely unimportant to extremely important) and multiplied by the matching belief statement responses to create scores for 'beliefevaluations ${ }^{22,23}$. Such belief evaluations are considered to be good predictors of overall (or direct) attitudes. Other measures included in the TPB model and the questionnaire were: overall attitudes, perceived control (perceived ability to increase $\mathrm{F} \& \mathrm{~V}$ ), subjective norm (the influence of important people), and intention to increase consumption. Questions were of the form 'My attitude to increasing the amount of...', and the responses scored on a 7-point scale from extremely unfavourable $(-3)$, through neutral $(0)$, to extremely favourable $(+3)$. Perceived intakes were assessed by two measures: first, perception of whether absolute intakes were high or low; and second, whether they were relatively high or low. For example: 'Compared to the average person (of your sex and age) in this country the amount of fruit I eat is...', scored on a 7-point scale from extremely low (1), through neutral (4) to extremely high (7). Examples of all questions are given in Appendix 1.

The second part of the questionnaire elicited selfreported frequency of intake of 116 named fruits and vegetables with defined portion sizes in the form of discrete items, e.g. two plums, or household measures familiar to UK consumers, for example two serving spoons of broccoli, equating to approximately $80 \mathrm{~g}^{24}$, with additional blank fields for products not listed. Respondents entered the number of occasions they consumed fresh, frozen, dried and canned forms of fruit, vegetables and vegetable dishes daily, weekly, monthly or yearly, or rarely/never in the preceding year. The reported frequencies of all items were summed and the total was converted to portions per day.

The third part of the questionnaire consisted of perceived appropriateness ${ }^{25}$ (uses and situations) of five items: fresh fruit, fresh vegetables, frozen vegetables, fruit juice and vegetable dishes but is not reported here. The final section asked for a wide range of sociodemographic data.

\section{Analysis}

Responses were analysed using SPSS statistical software (SPSS for Windows v.6.1; SPSS Inc., Chicago, 1993). Reported intakes of $F \& V$, as standard portions per day, were used to calculate thirds of the distribution with which subjects were categorized as high, medium and low consumers of vegetables, fruit, vegetable dishes and total F\&V (see Table 3). Data were analysed for descriptive means and frequencies, and one-way analysis of variance (ANOVA) (using a least significant difference test for post-hoc comparisons) was used to examine differences in attitudes, subjective norm and 
perceived control between high, medium and low consumers. To test scores for significant differences from neutral, $t$-tests were used. The 11 belief evaluation items were tested for reliability as intercorrelated items using Cronbach's alpha.

Both simple and hierarchical regression analysis were performed on components of the TPB model; first, the sum of belief evaluation against overall attitudes analysed separately (simple regression analysis: independent variables $\Sigma$ belief $\bullet$ evaluations, with attitudes as the dependent variable); and second, entering attitude and subjective norms at the first stage and perceived control at the second stage (the latter to account for any additional variance explained) to identify their relative importance for predicting intention to increase consumption of fruit, vegetables and vegetable dishes (hierarchical regression analysis: independent variables attitudes, subjective norms and perceived control, with intention as dependent variable).

\section{Results}

\section{Respondent cbaracteristics}

Of the 2020 addresses sampled, 24 were found to have 'moved away' or deceased, giving a sample of 1996, from which $37 \% \quad(n=741)$ responded with complete, usable questionnaires. Table 1 shows the profile of the sample subjects compared to the UK population. Almost $98 \%$ described themselves as white or European with only $2 \%$ black or Asian (population $\approx 5 \%$ ). Despite weighting the sample towards lower social classes an element of selfselection resulted in this sector of the population being under-represented. Over-sampling Scotland was deliberate as this region is thought to have particularly low F\&V consumption. Analysis of regional groupings did not reveal any significant overall differences between regions although some differences were seen within regions between sociodemographic groups. These further regional analyses will be reported elsewhere. The modest response rate negated stratification, yielding a .convenience sample.

\section{Belief evaluations}

The 11 belief and corresponding outcome evaluation questions are presented in Table 2, and reveal high positive scores for taste, health, nutritional value and family liking, especially for fruit and vegetables. Vegetable dishes scored lower generally, whilst fruit scores very low for 'inexpensive' and 'filling'; i.e. suggesting some respondents considered fruit to be expensive and not very filling. Observations on the distributions of the crude belief scores confirmed that negative beliefs (scored -1 to -3 ) were particularly
Table 1 Profile of subjects completing the questionnaire $(n=741$, $37 \%$ response rate)

\begin{tabular}{|c|c|c|}
\hline & Sample (\%) & Population $(\%)^{25}$ \\
\hline \multicolumn{3}{|l|}{ Sex } \\
\hline male & 53 & 52 \\
\hline female & 47 & 48 \\
\hline \multicolumn{3}{|l|}{ Age (years) } \\
\hline $16-29$ & 20 & 27 \\
\hline $30-44$ & 28 & 26 \\
\hline $45-64$ & 31 & 27 \\
\hline 65 & 21 & 19 \\
\hline \multirow{2}{*}{\multicolumn{3}{|c|}{$\begin{array}{l}\text { Social class }{ }^{26} \\
\text { (head of household) }\end{array}$}} \\
\hline & & \\
\hline I (executive) & 12 & 3 \\
\hline II (professional) & 23 & 14 \\
\hline IIN (skilled non-manual) & 17 & 23 \\
\hline IIIM (skilled manual) & 33 & 32 \\
\hline \multicolumn{3}{|l|}{ IV\&V (semi-skilled } \\
\hline \& unskilled manual) & 13 & 29 \\
\hline \multicolumn{3}{|l|}{ Combined regions } \\
\hline Scotland & 20 & 9 \\
\hline Northern England ${ }^{\mathrm{a}}$ & 27 & 26 \\
\hline Midlands and Wales ${ }^{b}$ & 24 & 22 \\
\hline Southern England ${ }^{c}$ & 29 & 45 \\
\hline
\end{tabular}

aNorthem England is the combined regions of the North; North West; Yorkshire and Humberside.

"Midlands and Wales are the combined regions of the East Midlands; West Midlands; Wales.

"Southem England is the combined regions of East Anglia; London and South East; South West.

notable for fruit with regard to cost ( $31 \%$ of the sample) and satiety ( $28 \%$ of the sample). Cost also scored as a negative factor for almost a quarter of respondents (23\%) for vegetable dishes. The significant differences between many of the values suggest that these foods are perceived to have differing attributes, although the various belief statements were scored in a similar relative order.

\section{FEV frequency questionnaire}

Each third was determined by the distributions of each foods' reported consumption and the total combined F\&V reported consumption. The mean (SD) reported portion intakes for low, medium and high thirds were, for fruit: $0.96(0.47), 2.33(0.47)$, and $4.46(1.1)$; for vegetables: $1.61(0.6), 3.39(0.47)$ and $5.99(1.4)$; for vegetable dishes $0.28(0.15), 0.67(0.15)$ and $1.39(0.47)$; and for total F\&V $3.63(1.2), 6.72(0.8)$ and 11.27 (3.5), respectively, and were much higher than expected.

All mean scores for attitude, intention, perceived control and subjective norm (Table 3 ) were positive and significantly different from the mid-point of the scales $(P<0.05)$, with the single exception of subjective norm (social pressure) to increase vegetable dishes (i.e. there was no perceived social pressure to increase consumption of these foods). For all foods, mean scores for subjective norm were very close to the mid-point, suggesting very little social pressure to increase consumption. Comparison of scores by thirds of consumption (see Table 3) indicates that higher 
Table 2 Mean (SD) belief evaluation scores for increasing fruit, vegetables and vegetable dishes

\begin{tabular}{|c|c|c|c|}
\hline $\begin{array}{l}\text { Belief } \\
\text { statement }\end{array}$ & $\begin{array}{l}\text { Fruits } \\
\text { mean (SD) } \\
\text { scores }\end{array}$ & $\begin{array}{l}\text { Vegetabies } \\
\text { mean (SD) } \\
\text { scores }\end{array}$ & $\begin{array}{c}\text { Vegetable dishes } \\
\text { mean (SD) } \\
\text { scores }\end{array}$ \\
\hline $\begin{array}{l}\text { I like the taste of } \\
\text { Protect my health } \\
\text { Increase my nutrient }\end{array}$ & $\begin{array}{l}1 \\
1 \\
1\end{array}$ & $\begin{array}{l}1 \\
1\end{array}$ & $\begin{array}{r}11.731 \\
9.09\end{array}$ \\
\hline $\begin{array}{l}\text { like } \\
\text { ating habits } \\
\text { weight }\end{array}$ & $\begin{array}{c}11.58(7.55) \\
11.44^{\mathrm{a}}(8.48) \\
9.46^{\mathrm{a}}(8.40)\end{array}$ & $\begin{array}{c}12.27(7.25) \\
11.25^{\mathrm{a}}(8.42) \\
9.66^{\mathrm{a}}(8.15)\end{array}$ & $\begin{array}{l}9.64(8.01) \\
9.14(8.90) \\
7.19(9.01)\end{array}$ \\
\hline $\begin{array}{l}\text { control } \\
\text { Easy to pre } \\
\text { (and coo }\end{array}$ & & & \\
\hline $\begin{array}{l}\text { Not boring } \\
\text { Easy to chew }\end{array}$ & $817(839)$ & $7.20(8.84)$ & 6151 \\
\hline $\begin{array}{l}\text { and digest } \\
\text { Filling } \\
\text { Inexpensive }\end{array}$ & $\begin{array}{l}6.86(8.47) \\
3.05(8.75) \\
2.79(9.20)\end{array}$ & $\begin{array}{l}8.11(7.96) \\
8.28(7.96) \\
6.53(8.36)\end{array}$ & $\begin{array}{l}8.76(7.68) \\
4.26(8.97)\end{array}$ \\
\hline
\end{tabular}

Row values all significantly different $(P<0.05)$ except as noted ${ }^{\mathrm{a}}$. Possible values range from -21 to +21 .

'Originally phrased 'I find boring', reported scores have been reversed.

consumption related to more favourable attitudes, particularly for vegetable dishes. Intention did not differ across consumption thirds for fruit, nor between low and middle thirds for vegetable dishes, but was lowest for middle consumers of vegetables. Perceived control (ability to increase) and subjective norms did not differ by consumption group for any of the three foods.

Large proportions (\%) of respondents reported positive attitude scores $(+1$ to +3$)$ towards increasing fruit $(78 \%)$ and vegetables $(77 \%)$ and, to a slightly lesser extent, vegetable dishes (65\%). Similarly positive scores for perceived control were high for fruit $(68 \%)$, vegetables (69\%) and vegetable dishes (65\%). Furthermore, intention to increase consumption was expressed by large proportions of the sample for fruit $(60 \%)$, vegetables $(57 \%)$ and vegetables dishes $(44 \%)$. The internal consistency of the 11 belief evaluation items measured by Cronbach's alpha was high for all three foods and were, for fruit 0.78 , vegetables 0.84 and vegetable dishes 0.87 .

Multiple regression analyses amongst components of the TPB model for the whole sample (Table 4) reveals that belief evaluations were significantly associated with overall attitudes; overall attitudes predicted reported intention to increase consumption; and subjective norm (social pressure) was related to reported intention. However, despite low mean values for subjective norm (see Table 3 ) this item substantially adds to $R^{2}$ beyond attitudes. Although significant, associations between perceived control (perceived ability to increase consumption) and intention were much weaker, especially for fruit. Belief evaluations and overall attitudes were particularly important towards vegetable dishes.

The data (Table 5) on perceived intakes (relative to other people of the same age and sex) indicate a reasonable level of relative agreement between perceived intakes and reported consumption; however, there is clearly an upward shift in the absolute level of perceived intakes. Regardless of current intake, the majority of respondents see themselves as consuming more fruits and vegetables than the average person. Table 5 indicates that many individuals in the lower intake categories for fruits and vegetables perceived themselves as having high intakes. This may be important, as Table 6 shows that fewer than half of

Table 3 Mean (SD) scores, ANOVA F-ratios and significance levels for thirds of total F\&V consumption (low, medium and high) for components of the TPB model for increasing consumption of fruit, vegetables and vegetable dishes

\begin{tabular}{|c|c|c|c|c|c|}
\hline $\begin{array}{l}\text { Food and model } \\
\text { component }\end{array}$ & $\begin{array}{c}\text { Total sample } \\
n=741 \\
\text { mean (SD) score }\end{array}$ & $\begin{array}{c}\text { Low third } \\
n=247 \\
\text { mean (SD) score }\end{array}$ & $\begin{array}{c}\text { Medium third } \\
n=247 \\
\text { mean (SD) score }\end{array}$ & $\begin{array}{c}\text { High third } \\
n=247 \\
\text { mean (SD) score }\end{array}$ & $\begin{array}{c}F \text {-ratio and } \\
\text { significance } \\
\text { level }\end{array}$ \\
\hline $\begin{array}{l}\text { Fruit } \\
\text { Intention } \\
\text { Attitude } \\
\text { Perceived control } \\
\text { Subjective norm }\end{array}$ & $\begin{array}{l}0.82(1.43) \\
1.48(1.37) \\
1.22(1.60) \\
0.35(1.73)\end{array}$ & $\begin{array}{l}0.87(1.40) \\
1.33^{a}(1.41) \\
1.17(1.62) \\
0.49(1.67)\end{array}$ & $\begin{array}{l}0.72(1.44) \\
1.41^{a}(1.32) \\
1.16(1.62) \\
0.27(1.76)\end{array}$ & $\begin{array}{l}0.85(1.47) \\
1.67^{b}(1.30) \\
1.34(1.52) \\
0.27(1.63)\end{array}$ & $\begin{array}{l}0.76 \\
3.9^{* *} \\
0.91 \\
1.23\end{array}$ \\
\hline $\begin{array}{l}\text { Vegetables } \\
\text { Intention } \\
\text { Attitude } \\
\text { Perceived control } \\
\text { Subjective norm }\end{array}$ & $\begin{array}{l}0.73(1.48) \\
1.47(1.36) \\
1.24(1.58) \\
0.32(1.73)\end{array}$ & $\begin{array}{l}0.78^{\mathrm{a}}(1.48) \\
1.37^{\mathrm{a}}(1.38) \\
1.23(1.59) \\
0.44(1.68)\end{array}$ & $\begin{array}{l}0.56^{\mathrm{b}}(1.51) \\
1.35^{\mathrm{a}}(1.37) \\
1.17(1.62) \\
0.23(1.75)\end{array}$ & $\begin{array}{l}0.88^{\mathrm{a}}(1.42) \\
1.67^{\mathrm{b}}(1.39) \\
1.34(1.58) \\
0.26(1.76)\end{array}$ & $\begin{array}{l}2.8^{*} \\
4.2^{*} \\
0.66 \\
1.01\end{array}$ \\
\hline $\begin{array}{l}\text { Vegetable dishes } \\
\text { Intention } \\
\text { Attitude } \\
\text { Perceived control } \\
\text { Subjective norm }\end{array}$ & $\begin{array}{l}0.36(1.53) \\
0.98(1.53) \\
0.83(1.64) \\
0.13 \times(1.65)\end{array}$ & $\begin{array}{l}0.32^{\mathrm{a}}(1.58) \\
0.86^{\mathrm{a}}(1.61) \\
0.74(1.74) \\
0.25 \times(1.62)\end{array}$ & $\begin{array}{l}0.13^{\mathrm{a}}(1.52) \\
0.78^{\mathrm{a}}(1.50) \\
0.78(1.63) \\
0.02 \times(1.69)\end{array}$ & $\begin{array}{l}0.65^{\mathrm{b}}(1.47) \\
1.31^{\mathrm{b}}(1.43) \\
1.00(1.56) \\
0.10 \times(1.63)\end{array}$ & $\begin{array}{l}6.7^{* *} \\
8.2^{* * *} \\
1.59 \\
1.24\end{array}$ \\
\hline
\end{tabular}

The possible ranges for the means are -3 to +3 .

Values not sharing a common letter $\left({ }^{\mathrm{a}, \mathrm{b}}\right)$ are significantly different among consumption groups for food and model components with significant overall ratio: $* P<0.05, \cdots P<0.01, \cdots P<0.001$.

Scores followed by $x$ indicates not significantly different from the neutral mid-point of the scale (0). 
Table 4 Results of correlation and simple and hierarchical regression analyses between psychosocial components of the TPB model and intention to increase intakes of fruit, vegetables and vegetable dishes for the whole sample $(n=741)$

\begin{tabular}{|c|c|c|c|c|c|c|c|c|c|c|c|}
\hline \multirow[b]{3}{*}{ Foods } & \multirow{2}{*}{\multicolumn{2}{|c|}{$\begin{array}{c}\text { Simple } \\
\begin{array}{c}\Sigma \text { belief } \\
\text { evaluations }\end{array}\end{array}$}} & \multicolumn{9}{|c|}{ Stepwise $^{b}$} \\
\hline & & & \multicolumn{3}{|c|}{ Step 1: attitudes } & \multicolumn{3}{|c|}{ Step 1: subject norm } & \multicolumn{3}{|c|}{ Step 2 perceived control } \\
\hline & $B$ & $\overline{R^{2}}$ & $r$ & $B$ & $R^{2 \dagger}$ & $r$ & $B$ & $R^{2 \dagger}$ & $r$ & $B$ & $R^{2 \dagger}$ \\
\hline $\begin{array}{l}\text { Fruit } \\
\text { Vegetables } \\
\text { Vegetable dishes }\end{array}$ & $\begin{array}{l}0.39^{* \pm *} \\
0.38^{* * *} \\
0.48^{* * *}\end{array}$ & $\begin{array}{l}0.16 \\
0.15 \\
0.23\end{array}$ & $\begin{array}{l}0.45^{\star * *} \\
0.48^{* * *} \\
0.59^{* * *}\end{array}$ & $\begin{array}{l}0.34^{* * * *} \\
0.34^{* * *} \\
0.45^{* * *}\end{array}$ & $\begin{array}{l}0.20 \\
0.23 \\
0.35\end{array}$ & $\begin{array}{l}0.42^{* * *} \\
0.40^{* * *} \\
0.45^{* * *}\end{array}$ & $\begin{array}{l}0.37^{* * *} \\
0.32^{* * *} \\
0.32^{* * *}\end{array}$ & $\begin{array}{l}0.34 \\
0.33 \\
0.46\end{array}$ & $\begin{array}{l}0.34^{* * *} \\
0.39^{* * *} \\
0.47^{* * *}\end{array}$ & $\begin{array}{l}0.12^{*} \\
0.16^{* * *} \\
0.12^{* * *}\end{array}$ & $\begin{array}{l}0.35 \\
0.33 \\
0.47\end{array}$ \\
\hline
\end{tabular}

- Simple regression analysis: independent variables $\Sigma$ belief $\bullet$ evaluations, with attitudes as the dependent variable.

- Stepwise regression analysis: independent variables attitudes, subjective norms and; at the second stage, perceived control, with intention as dependent variable.

** Correlation $(r)$ and $B$ weights significant at $P<0.001$, except for ${ }^{*} P<0.05$.

$\dagger$ Explained accumulated variance for step 1 (attitudes and subjective norm) and, step 2 (perceived control) regressions.

those who perceived their intake as high, not surprisingly, felt they needed to increase their intakes.

\section{Discussion}

The TPB model reported here, as in similar studies of dietary change $e^{21,28,29,30}$, identified predictors of intention to increase $\mathrm{F} \& \mathrm{~V}$ consumption. Attitudes and subjective norm were particularly important, but the latter did not score highly as an important influence on individuals. The importance of attitudes to future increased $F \& V$ intake is consistent with another study on changing to 'healthier eating ${ }^{29}$ but contrasts with a 'reducing fat' study ${ }^{21}$ which found subjective norm to be more important with regard to this more high profile dietary change.

It is apparent that the intention scores do not represent perfect linear relationships between present estimated consumption and intention to increase intakes. The significantly lower intention score for increasing vegetable intakes for medium third consumers (see Table 4) relative to high and low thirds may reflect particular complacency amongst these consumers who feel their intakes are already high. In contrast, the high intention and attitude scores reported by the highest third of consumers may be reflective of knowledgeable individuals with generally greater interest in attaining and maintaining healthy lifestyle behaviours. Intention has been demonstrated to be an important factor in behavioural (dietary) change in this and other studies ${ }^{30,31}$ but may only represent a desire to eat differently and may not translate into actual behavioural change. A recent study ${ }^{32}$ used a health belief model to contrast positive attitudes towards F\&V with barriers, and found that perceived barriers accounted for the largest component of variability in actual F\&V consumption. Similarly, and also in contrast to our study findings, a Dutch study ${ }^{33}$, which included modified components of the TPB model, found that self-efficacy (similar in construct to perceived control) explained the greatest variance in the intention to increase intakes of $F \& V$. Differences may relate both to the samples and the specific phrasing of the question(s), or the perceived ability to increase intakes reported by respondents in this study may be related to optimistic bias, i.e. respondents felt over-confident about their ability to increase.

Recent studies on $\mathrm{F} \& \mathrm{~V}^{34}$ and fat and fibre $\mathrm{S}^{35}$ have also suggested that 'stage of change' (pre-contemplation, contemplation, preparation, action or maintenance of a particular behaviour) may be an important factor in determining which psychosocial factor may be important for particular subgroups. Whilst we had no

Table 5 Perceived fruit and vegetable intake scores 'compared to the average person' by third of reported fruit or vegetable intake

\begin{tabular}{|c|c|c|c|c|c|}
\hline \multirow{2}{*}{$\begin{array}{l}\text { Reported intake } \\
\text { (food frequency) by thirds }\end{array}$} & \multicolumn{2}{|c|}{ Perceived intake ${ }^{1}$ score } & \multicolumn{3}{|c|}{ Perceived intake category (\%) } \\
\hline & Mean & (SD) & Low & Medium & High \\
\hline $\begin{array}{l}\text { Fruit } \\
\text { Low } \\
\text { Medium } \\
\text { High }\end{array}$ & $\begin{array}{l}4.23^{\mathrm{a}} \\
4.53^{\mathrm{b}} \\
4.75^{\mathrm{c}}\end{array}$ & $\begin{array}{l}(1.50) \\
(1.33) \\
(1.41)\end{array}$ & $\begin{array}{l}34 \\
20 \\
15\end{array}$ & $\begin{array}{l}31 \\
35 \\
27\end{array}$ & $\begin{array}{l}36 \\
45 \\
59\end{array}$ \\
\hline $\begin{array}{l}\text { Vegetables } \\
\text { Low } \\
\text { Medium } \\
\text { High }\end{array}$ & $\begin{array}{l}4.36^{\mathrm{a}} \\
4.63^{\mathrm{b}} \\
5.12^{\mathrm{c}}\end{array}$ & $\begin{array}{l}(1.45) \\
(1.30) \\
(1.32)\end{array}$ & $\begin{array}{r}25 \\
15 \\
9\end{array}$ & $\begin{array}{l}31 \\
36 \\
38\end{array}$ & $\begin{array}{l}44 \\
49 \\
52\end{array}$ \\
\hline
\end{tabular}

'Perceived intake score categories: low, score < 4; medium (neither high nor low), score = 4; high, score > 4. a,b,c Mean scores are all significantly different from each other $(P<0.05)$ and above the mid-point of the scale. 
Table 6 Agreement with need to increase fruit and vegetable intake, in relation to perceived intake

\begin{tabular}{lcc}
\hline & \multicolumn{2}{c}{$\begin{array}{c}\% \text { of positive responses to } \\
\text { Do you think you should eat more... }\end{array}$} \\
\cline { 2 - 3 } Perceived intake & fruit? (Yes) & vegetables? (Yes) \\
\hline Low & 90 & 86 \\
Medium & 42 & 52 \\
High & 49 & 43 \\
\hline
\end{tabular}

such measure in this study, it is possible that such an additional measure could have been useful.

Potential barriers to increased consumption were identified in this study. There appears to be a perception by a substantial proportion of the sample that both fruit, and to a lesser extent vegetable dishes, are expensive. This is consistent with both Scottish ${ }^{18}$ and American studies ${ }^{36}$. Historically high fruit prices ${ }^{37}$, combined with the perception that fruit was not seen as filling and therefore poor value for money, may create the perception that fruit is expensive, and may be independent of the low incomes of some consumers ${ }^{18}$. However, the real cost of fruit in the UK has recently fallen $^{16,37}$. Vegetable dishes do not (yet) seem to be highly promising as a vehicle for increased consumption. It appears that family influences (see Table 2) shape attitudes towards $F \& V$, suggesting that educational messages should accommodate the whole family rather than individuals.

Another important barrier seemed to be a general lack of social pressure to increase consumption, suggesting that consumers may not (yet) be aware of health messages to increase $F \& V$ or that these messages are not effective. This may be related to the perception that many regard their present consumption to be greater than average, regardless of actual intake (see Table 5) and, as intention to increase is related to present consumption (see Table 6), they may lack the motivation to increase. Those in the lowest third of intakes generated responses above the scale mid-point for intakes 'in comparison to an average person'. Such optimistic bias has been described by researchers studying various behaviours including eating and risk of disease $\mathrm{e}^{38,39}$. These studies noted that underestimation of 'unhealthy' foods tends to be associated with overestimations of 'healthy' foods, for example $F \& V^{38}$. An F\&V study in The Netherlands ${ }^{41}$, reaching similar conclusions, suggested that nutrition education should first focus on raising awareness of present consumption. In previous work, Scottish consumers ${ }^{18}$ were found to be complacent about their consumption regardless of their intake. A qualitative study ${ }^{41}$ found that Dutch consumers lacked both awareness of recommended intakes and specific health benefits, concluding that specific, high profile health messages were needed.

\section{Study limitations}

Measuring subjective norm by only one measure ('people who are important to you...'), did not refer directly to any specific '5-a-day' or other public health messages, and perhaps future work should include evaluation of such campaigns.

There may be an element of self-selection in the respondent sample. The moderate response rate (37\%) may have consisted of those that had a particular interest in $F \& V$ therefore caution should be exercised in attributing the results as reflecting the attitudes of the whole UK population. A telephone follow-up of nonrespondents to a postal survey of medical practitioners ${ }^{42}$ claimed that significant differences between the two samples could be attributed to the specific interest in the subject matter by the postal respondents. Response bias also skewed our sample somewhat towards higher social classes and this may have raised some overall group means. Improved response rates could, in future, be achieved through reducing the number of questions (the questionnaire took approximately $40 \mathrm{~min}$ to complete), providing incentives in the form of charitable donations ${ }^{43}$ or prize draw entry or, ideally, re-sampling until an appropriate stratified sample was achieved.

There may also have been an element of positive response bias due to the phrasing of the questions. However, there was evidence of positive responses to outcome evaluation items that were phrased negatively ('I find boring') and negative responses to positive items ('inexpensive'). Considerable care was taken in phrasing the questions in response to both feedback from the pre-testing and for comparison with previous studies. Furthermore, caution should be exercised in interpreting these self-report data in respect to social desirability of eating more $F \& V^{44,45}$. The problem of positive response bias may, in future studies, be ameliorated by incorporating such 'desirable behaviour' amongst other unrelated topics in 'omnibus' questionnaires $^{18}$.

The mean portions per day were much higher than known per capita intakes. Overestimation may have occurred because of the method adopted. A comparison $^{46}$ of three large-scale American F\&V frequency questionnaires concluded that there was a positive relationship between the number of items listed and recall. Furthermore, summing responses to all individual fruits and vegetables (as we have done) in contrast to asking simple questions on the number of servings per day gave much higher and less reasonable results. On this basis the sample is unlikely to consist of high F\&V consumers but rather the method itself is flawed. If consumers are subdivided by class and region then trends in consumption from our data match the expected trends ${ }^{16,47}$. For example, our study found that reported consumption amongst manual occupations was lower 
than that of non-manual occupations, and that mean Scottish consumption was lower than that in southern England. Overestimates probably do not reflect season, due to high rates of importation, particularly of fruit ${ }^{48}$, and neither American ${ }^{23}$ or Dutch ${ }^{49}$ studies have found seasonal effects on consumption. Thus, we acknowledge that our methodology greatly overestimated absolute consumption and that other methods should be adopted in the future.

\section{Conclusions}

The present results show that UK consumers report generally positive attitudes to increasing $\mathrm{F} \& \mathrm{~V}$ consumption. The TPB model proved to be a useful predictor of intention with attitudes as the most important factor with all three foods. Perceived social pressure was positive, but low in absolute value. Cost was a negative factor for almost a third of respondents with regard to fruit and almost a quarter of respondents with regard to vegetable dishes. The low level of social pressure coupled with over-optimistic perceptions of current consumption suggest that more dietary change might occur if people were informed as to how little they presently eat and if there were clear definitions of what is meant by 5 portions. Efforts of producers and retailers to promote fruit and vegetable dishes as value for money could also make a positive contribution to dietary change.

\section{Acknowledgements}

This study was funded by the UK Ministry of Agriculture, Fisheries and Food. The authors would also like to thank Ms Jackie Aaron for initial work on the questionnaire, Ms Sarah Cuss and Mr Miles Ellison for their help with data collation, and Dr Paul Sparks and Mr Duncan Hedderley for their advice with statistical analysis.

\section{References}

1 WHO. Diet, Nutrition and the Prevention of Chronic Diseases. Technical Report Series 797. Geneva: World Health Organization, 1991.

2 The Scottish Office. Scotland's Health: a Challenge to Us All: The Scottish Diet. Report of a Working Party to the Chief Medical Officer for Scotland. London: HMSO, 1993: 54-76.

3 Block G, Patterson B, Subar A. Fruit, vegetables and cancer prevention: a review of the epidemiological evidence. Nutr. Cancer 1992; 18: 1-29

4 Ferro-Luzzi A, Cialfa E, Leclercq C, Toti E. The Mediterranean diet revisited: focus on fruit and vegetables. Int.J. Food Sci. Nutr. 1994; 45: 291-300.

5 Morris DM, Kritchevsky SB, Davis CE. Serum carotenoids and coronary heart disease: the Lipid Research Clinic's Coronary Primary Prevention trial and follow-up study. $J$. Am. Med. Assoc. 1994; 274: 1439-41.

6 Potter JD. Content with a Vegetable Love: Plant Foods and Cancer Risk. The Caroline Walker Lecture. London: The Caroline Walker Trust, 1994.
7 National Research Council. Diet and Healtb: Implications for Reducing Chronic Disease Risk. Washington DC: National Academy Press, 1989.

8 DHHS. Healthy People 2000 National Health Promotion and Disease Prevention Objectives. Washington DC: US Department of Health and Human Services, 1991 DHHS publication PHS 91.50213.

9 Cardiovascular Review Group Committee on Medical Aspects of Food Policy. Report on Health and Social Subjects: 46 Nutritional Aspects of Cardiovascular Disease. London: HMSO, 1994: 19-21, 133-6.

10 Havas S, Heimendinger J, Damron D et al. 5 a day for better health - nine community research projects to increase fruit and vegetable consumption. Public Health Rep. 1995; 110 $68-79$.

11 Heimendinger J, Van Duyn MAS. Dietary behavior change: the challenge of recasting the role of fruit and vegetables in the American diet. Am. J. Clin. Nutr. 1995; 61(S): 1397S$1401 S$.

12 Health Education Authority. Enjoy Fruit and Vegetables Campaign. London; HEA, 1992.

13 Health Education Board for Scotland. Enjoy Fruit and Vegetables Campaign. Edinburgh: HEBS, 1992.

14 Bean A. 5-a-day Eating Plans. London: Fresh Fruit and Vegetable Information Bureau, 1993.

15 Gregory J, Foster K, Tyler H, Wiseman M. The Dietary and Nutritional Survey of British Adults. London: OPCS/HMSO, 1990: 123-52.

16 Ministry of Agriculture Fisheries and Food. National Food Survey 1994. London: HMSO, 1995: 10-16.

17 Anderson AS, Hunt K, Ford G, Finnigan F. One apple a day? Fruit and vegetable consumption in West of Scotland. Health Educ. Res. 1994; 9: 297-305.

18 Anderson AS, Lean MEJ, Foster A, Marshall D. Ripe for change: fruit and vegetables in Scotland - current patterns and potential for change. Health Bull. 1994; 52: 51-64.

19 Williams C. Healthy eating: clarifying advice about fruit and vegetables. Br. Med. J. 1995; 310: 1453-5.

20 Ajzen I. From intentions to action: a theory of planned behavior. In: Kuhle J, Beckman J, eds. Action Control: From Cognition to Bebavior. Heidelburg: Springer, 1985: 11-39.

21 Lloyd HM, Paisley CM, Mela DJ. Changing to a low fat diet attitudes and beliefs of UK consumers. Euro. J. Clin. Nutr. 1993; 47: 361-73

22 Sparks P, Hedderley D, Shepherd R. Expectancy-value models of attitudes: a note on the relationships between theory and methodology. Euro. J. Soc. Psycho. 1991; 21: 261-71.

23 Ajzen I, Fishbein M. Understanding Attitudes and Predicting Social Bebavior. Englewood Cliffs: Prentice Hall, 1980.

24 Williams C. Healtby Eating: the Need to Clarify Advice about Fruit and Vegetables. Discussion Document. London: the Association of Consumer Research, May 1994.

25 Shutz HG. Appropriateness as a measure of the cognitivecontextual aspects of food acceptance. In: MacFie $\mathrm{HJH}$, Thomson DMH, eds. Measurement of Food Preferences. London: Blackie, 1994: 25-50.

26 Office of Population Census and Statistics. 1991 Census National Monitor for Great Britain. London: OPCS/HMSO, 1992.

27 Office of Population Census and Statistics. Appendix A. Allocation of standard classification occupational unit groups to social classes and socio-economic groups. In: Standard Occupational Classification. London: HMSO, 1990.

28 Saunders RP, Rahilly SA. Influence on intention to reduce dietary intake of fat and sugar. J. Nutr. Educ. 1990; 22: 16976.

29 Anderson AS, Shepherd R. Beliefs and attitudes toward 'healthier eating' among women attending maternity hospital. J. Nutr. Educ. 1989; 21: 208-13. 
30 Shepherd R. Attitudes and beliefs as determinants of food choice. In: McBride RL, MacFie HJH, eds. Psychological Basis of Sensory Evaluation. New York: Elsevier 1990: 141-61.

31 Shepherd R, Sparks P. Modelling food choice. In: MacFie $\mathrm{HJH}$, Thomson DMH, eds. Measurement of Food Preferences. London: Blackie, 1994: 202-62.

32 Dittus DL, Hilliers VN, Beerman KA. Benefits and barriers to fruit and vegetable intake: relationship between attitudes and consumption. J. Nutr. Educ. 1995; 27: 120-6.

33 Brug J, Lechner L, de Vries H. Psychosocial determinants of fruit and vegetable consumption. Appetite 1995; 25: 285-96

34 Brug J, Glanz K, Kok G. The relationship between selfefficacy, attitudes, intake compared to others, consumption, and stages of change related to fruit and vegetables $A m . J$. Health Promot. 1997; 12: 25-30

35 Glanz K, Patterson RE, Kristal AR et al. Stages of change in adopting healthy diets: fat, fiber and correlates of nutrient intake. Health Educ. Q. 1994; 21 : 499-519.

36 Reicks M, Randall JL, Hayes BJ. Factors affecting consumption of fruits and vegetables by low-income families. J. Am. Diet Assoc. 1994; 94: 1309-11.

37 Ritson C, Hutson R. The consumption revolution. In: Slater JM, ed. Fifty Years of The National Food Survey 1940-1990. London: HMSO, 1991: 35-54.

38 Sparks P, Shepherd R, Wieringa N, Zimmermanns N. Perceived behavioural control, unrealistic optimism and dietary change: an exploratory study. Appetite 1995; 24: 243-55.

39 Brug J, van Assema P, Kok E, Landerlink T, Glanz K. Self rated dietary fat intake: association with objective assessment of fat, psychosocial factors, and intention to change. J. Nutr. Educ. 1994; 26: 218-23.

40 Sparks P, Hedderly D, Shepherd R. An investigation into the relationship between perceived control, attitudes variability and the consumption of two common foods. Euro. J. Soc. Psycbo. 1992; 22: 55-71.

41 Lechner L, Brug J, De Vries H. Determinants of the objective and subjective consumption of fruit and vegetables. Appetite 1995; 24: 267-8.

42 Stibbald B, Addingtonhall J, Brenneman D, Freeling P. Telephone versus postal surveys of general practitioners methodological considerations. Br. J. Gen. Pract. 1994; 44 297-300.

43 Dickinson JR, Faria AJ. Refinements of charitable contribution incentives for mail surveys. J. Market Res. Soc. 1995; 37: 447-53.

44 Worsley A, Baghurst KI, Leitch DR. Social desirability response bias and dietary inventory responses. Hum. Nutr. Appl. Nutr. 1984; 38A: 29-35.

45 Kristiansen CM, Harding CM. The social desirability of preventative health behavior. Publ. Health Rep. 1984; 99: 384-8.

46 Heimendinger J, Subar AF, Patterson BH, Pivonka E. Using food frequency questionnaires to estimate fruit and vegetable intake: association between the number of questions and total intakes. J. Nutr. Educ. 1995; 27: 80-5.

47 Ministry of Agriculture, Fisheries and Food. The Dietary and Nutritional Survey of British Adults - Furtber Analysis. London: HMSO, 1994.

48 Keynote publications. Fruit and Vegetables - Report. Hampton: Keynote Publications, 1994: 1-29.

49 Brug J, Debie S, van Assema P, Weijts W. Psychosocial determinants of fruit and vegetable consumption among adults: results of focus group interviews. Food Qual. Pref. 1995; 6: 99-107.

Appendix 1: Examples of the theory of planned behaviour questions

1 An example of an intention question: Please indicate if you agree or disagree with the following ' $I$ intend to eat more...'

(a) Fruit in the next year, etc.

2 An example of an attitude question: 'My attitude towards increasing the amount of...'

(a) Fruit I eat, etc.

3 An example of a subjective norm question: Please indicate if you agree or disagree with the following: 'People who are important to me think I should increase the amount of...'

(a) Fruit I eat, etc.

4 An example of a perceived control question:

'For me to increase the amount of...'

(a) Fruit I eat, etc.

5 An example of a belief question:

'Increasing the amount of fruit I eat means choosing foods which...'

(a) protect my health

(b) are inexpensive

(c) are filling

6 An example of a corresponding evaluation question:

'Choosing foods which...'
(a) protect my health
(b) are inexpensive
(c) are filling. 